\title{
ON $n$-TH JAMES AND KHINTCHINE CONSTANTS OF BANACH SPACES
}

\section{Maligranda, L. I. NiKolova, L.-E. Persson And T. Zachariades}

Abstract. For any Banach space $X$ the $n$-th James constants $J_{n}(X)$ and the $n$-th Khintchine constants $K_{p, q}^{n}(X)$ are investigated and discussed. Some new properties of these constants are presented. The main result is an estimate of the $n$-th Khintchine constants $K_{p, q}^{n}(X)$ by the $n$-th James constants $J_{n}(X)$. In the case of $n=2$ and $p=q=2$ this estimate is even stronger and improvs an earlier estimate proved by Kato-Maligranda-Takahashi [25].

Mathematics subject classification (2000): 46B20, 46E30, 46A45, 46B25.

Key words and phrases: Banach spaces, James constant, Jordan-von Neumann constant, uniformly non-square spaces, $n$-th James constants, B-convex spaces, Khintchine constants, type.

\section{REFERENCES}

[1] A. BECK, A convexity condition in Banach spaces and the strong law of large numbers, Proc. Amer. Math. Soc. 13 (1962), 329-334.

[2] B. BeAuZAmy, Introduction to Banach Spaces and their Geometry, North-Holland Publ., AmsterdamNew York 1982.

[3] Y. Benyamini and J. Lindenstrauss, Geometric Nonlinear Functional Analysis, Vol. 1, Amer. Math. Soc. Colloq. Publ. 48, AMS, Providence 2000.

[4] E. CASInI, About some parameters of normed linear spaces, Atti Accad. Naz. Lincei, VIII. Ser., Rend., Cl. Sci. Fis. Mat. Nat. 80 (1986), 11-15.

[5] J. A. Clarkson, Uniformly convex spaces, Trans. Amer. Math. Soc. 40 (1936), 396-414.

[6] J. Diestel, H. Jarchow And A. Tonge, Absolutely Summing Operators, Cambridge University Press, Cambridge 1995.

[7] A. DvoretzKy, Some results on convex bodies and Banach spaces, Proc. Symp. on Linear Spaces, Jerusalem 1961, 123-160.

[8] P. Enflo, J. Lindenstrauss And G. Pisier, On the "three space problem", Math. Scand. 36 (1975), no. 2, 199-210.

[9] T. FIGIEL, T. IWANIEC AND A. PEŁCZYŃSKI, Computing norms and critical exponents of some operators in $L^{p}$-spaces, Studia Math. 79 (1984), 227-274.

[10] T. FigIEL, J. Lindenstrauss AND V. D. MiLman, The dimension of almost spherical sections of convex bodies, Acta Math. 139 (1977), 53-94.

[11] J. GAO AND K. S. LAU, On the geometry of spheres in normed linear spaces, J. Austral. Math. Soc. Ser. A 48 (1990), 101-112.

[12] J. GAO AND K. S. LAU, On two classes of Banach spaces with uniform normal structure, Studia Math. 99 (1991), 41-56.

[13] D. P. GIESY, On a convexity condition in normed linear spaces, Trans. Amer. Math. Soc. 125 (1966), 114-146.

[14] D. P. GIESY AND R. C. JAMES, Uniformly non $l^{(1)}$ and B-convex Banach spaces, Studia Math. 48 (1973), 61-69.

[15] C. JAMES, Uniformly non-square Banach spaces, Ann. of Math. 80 (1964), 542-550. 
[16] R. C. JAMES, Some self-dual properties of normed linear spaces, In: Symposium on Infinite-Dimensional Topology (Louisiana State Univ., Baton Rouge 1967), Ann. Math. Studies 69, Princeton Univ. Press, Princeton 1972, 159-175.

[17] P. JoRdan AND J. VON NeUmanN, On inner products in linear metric spaces, Ann. of Math. 36 (1935), 719-723.

[18] V. M. KadeTS AND M. I. KadETS, Rearrangements of Series in Banach Spaces, Amer. Math. Soc., Providence, RI 1991.

[19] M. I. KADETS AND V. M. KADETS, Series in Banach spaces. Conditional and Unconditional Convergence, Birkhäuser Verlag, Basel 1997.

[20] N. J. Kalton, The three space problem for locally bounded F-spaces, Compositio Math. 37 (1978), 243-276.

[21] N. J. Kalton, Convexity, type and three space problem, Studia Math. 69 (1981), 247-287.

[22] N. J. Kalton, N. T. PeCK AND J. W. RoberTs, An F-space Sampler, Cambridge University Press, Lecture Notes Series, Vol. 89, 1984.

[23] A. KAmińsKa AND B. TuRetT, Uniformly non- $l^{1}(n)$ Orlicz-Bochner spaces, Bull. Polish Acad. Sci. Math. 35 (1987), no. 3-4, 211-218.

[24] M. Kato AND L. MaLigRanda, On James and Jordan-von Neumann constants of Lorentz sequence spaces, J. Math. Anal. Appl. 258 (2001), 457-465.

[25] M. KATO, L. MALIGRANDA AND Y. TAKAHASHI, On James and von Neumann-Jordan constants and the normal structure coefficient of Banach spaces, Studia Math. 144 (2001), 275-295.

[26] M. KATO AND Y. TAKAHASHI, On the von Neumann-Jordan constant for Banach spaces, Proc. Amer. Math. Soc. 125 (1997), 1055-1062.

[27] M. Kato, Y. TAKahashi AND K. Hashimoto, On n-th von Neumann-Jordan constants for Banach spaces, Bull. Kyushu Inst. Tech. Pure Appl. Math. 45 (1998), 25-33.

[28] H. KöNIG AND L. TZAFrIRI, Some estimates for type and cotype constants, Math. Ann. 256 (1981), $85-94$.

[29] D. KutZarova, L. Nikolova AND T. Zachariades, Real interpolation for families of Banach spaces and convexity, Math. Nachr. 171 (1995), 259-268.

[30] J. Lindenstrauss AND L. TZAFRIRI, Classical Banach Spaces II, Springer-Verlag, 1979.

[31] L. Maligranda, On an estimate of the Jordan-von Neumann constant by the James constant, Aug. 2003, 5 pages manuscript.

[32] L. Maligranda, On some constants related to Banach spaces, Lecture at the Naresuan University, Phitsanulok-Thailand, March 21, 2005 (notes of 30 pages).

[33] L. MaligRAnda AND L.-E. Persson, On Clarkson's inequalities and interpolation, Math. Nachr. 155 (1992), 187-197.

[34] L. Maligranda, N. Petrot And S. Suantai, On the James constant and B-convexity of Cesàro and Cesàro-Orlicz sequence spaces, J. Math. Anal. Appl. 326 (2007), 312-331.

[35] B. MauReY AND G. PISIER, Series de variables aléatoires vectorialles independantes et propriétés geométriques des espaces de Banach, Studia Math. 58 (1976), 45-90.

[36] V. D. Milman AND G. SCHECHTMAN, Asymptotic Theory of Finite-Dimensional Normed Spaces, Lecture Notes in Mathematics 1200, Springer-Verlag, Berlin 1986.

[37] L. NiKOlOVA, L. E. PERSSON AND T. ZACHARIADES, Estimates of some constants equipped with Banach spaces, Research Report, Luleå University of Technology 12 (2003), 1-13.

[38] L. Nikolova, L. E. Persson AND T. Zachariades, A study of some constants for Banach spaces, C. R. Acad. Bulg. Sci. 57 (2004), Vol. 2, 5-8.

[39] G. PISIER, Sur les espaces de Banach qui ne contiennent pas uniformément de $l_{n}^{1}, \mathrm{C}$. R. Acad. Sci. Paris Sér. A-B 277 (1973), A991-A994.

[40] G. PISIER, Sur les espaces qui ne contiennent pas de $l_{n}^{1}$ uniformément, Séminaire Maurey-Schwartz (1973-1974), Espaces $L^{p}$, Applications Radonifiantes et Géométrie des Espaces de Banach, Centre de Math., École Polytech., Paris 1974, Exp. No. 7, 19 pp.

[41] G. PISIER, Corrections et additions a l'expose III ("Le théorème de la limite centrale et la loi du logarithme itéré dans les espaces de Banach. I", Séminaire Maurey-Schwartz 1975-1976: Espaces $L^{p}$, Applications Radonifiantes et Géométrie des Espaces de Banach, Exp. No. 3, Centre Math., École Polytech., Palaiseau 1976), Séminaire Maurey-Schwartz (1975-1976), Centre Math., École Polytech., Palaiseau 1976, Annexe No. 1, 7 pp.

[42] S. SAEJUNG, On James and von Neumann-Jordan constants and sufficient conditions for the fixed point property, J. Math. Anal. Appl. 323 (2006), 1018-1024. 
[43] Y. TAKAHASHI, Some geometric constants of Banach spaces - A unified approach, In: Banach and Function Spaces II (Proc. Internat. Symposium Banach and Function Spaces II - ISBFS 2006, Sept. 14-17, 2006, Kitakyushu, Japan); Editors M. Kato and L. Maligranda, Yokohama Publishers 2007, to appear.

[44] N. TOMCZAK-JAEGERMAnN, Banach-Mazur Distances and Finite Dimensional Operator Ideals, Pitman Monographs and Surveys in Pure and Applied Mathematics 38, Longman, New York 1989.

[45] P. WojtaszCZYK, Banach Spaces for Analysts, Cambridge Univ. Press, Cambridge 1991.

[46] W. A. WoYCZYŃsKI, Geometry and martingales in Banach spaces. II. Independent increments, In: Probability on Banach Spaces, Adv. Probab. Related Topics, 4, Dekker, New York 1978, 267-517. 